\title{
Digital Collection Building Initiatives of National Library and Documentation Centre
}

\author{
Varuni Gangabadadarachchi \\ Head, Conservation and Preservation division \\ National Library and Documentation Centre \\ No. 14, Independence Avenue Col. 7 \\ Tel. 0112688855 ; Fax. 0112685201 \\ e-mail. Vganga2004@hotmail.com \\ M.S.U. Amarasiri \\ Director General/ CEO \\ National Library and Documentation Services Board \\ No. 14, Independence Avenue Col. 7 \\ Tel. 0112687581 Fax. 0112685201 \\ e-mail.dg@mail.natlib.lk
}

\begin{abstract}
The National Library has a major role in collecting and preserving nation's intellectual heritage. Digitization and digital libraries are more common with new changing environment in libraries. As printed materials continue to deteriorate rapidly, digitization of those materials would help to preserve originals and reformatted copies to use. National Library has commenced a project to develop a digital library. The major reference tools have been acquired in digital format. The national Library has also afforded to use of e-journals free of charge through the PERI project of INASP. Further Major bibliographic and documentation products of National Library are in print and digital formats or only in digital format. National Library catalogue and National Union Catalogue have been computerised and they can be accessed through web. The photographic collection of National Library also has been digitized. National Library has commenced a document scanning project which main objective is to enable users, regardless of location, to directly access and use digitised materials relating to Sri Lanka and Sri Lankans. A policy for digitization and collection management was formed. Mainly manuscripts are selected for digitization in the first phase of the project. Digital camera is an effective form of digital copying specially for larger items.
\end{abstract}

Key words: Digital collections/ digitization/National Library/digital camera/ accessibility/ manuscripts

\section{Introduction}

Revolution in ICT in the past couple of decades had drastic and farreaching impacts on all aspects of human life. The internet has added a new dimension to information technology giving birth to such rich concepts as digital Libraries, Knowledge Management etc. 
Digitization and digital libraries are more common with this new changing environment in libraries. It is also changing the way that libraries and archives not only work, but more fundamentally, the every work that they do.

Further, because printed materials continue to deteriorate rapidly, digitization of those materials would help to preserve originals and reformatted copies to use. So the reformatting of damaged or endangered books or documents is an effective and economic conservation measure, simultaneously digitization will help to increase accessibility to records, facilitates information sharing by keeping it at one secure place with few duplicate copies. Facilitates information dissemination, efficient and better access to traditional material sitting at one place has been made possible by digitisation.

The National Library has a major role in collecting and preserving nation's intellectual heritage. Therefore National Library has taken several steps to preserve this heritage as well as to increase the accessibility and awareness of these records. In the past this has meant collecting and preserving print and other physical objects while National Library will continue to collect materials in these formats, digitization will supplement with the precision of electronic access to the collection.

\section{Digital Collection Building Efforts}

National Library has commenced a project to developing a digital library. As a part of National Library collection building plan, National Library acquires library materials in printed, audio-visual and digital forms.

The major reference tools e.g. Science Citation Index and LISA have been acquired in digital format. The national Library has also afforded the opportunity to use large number of e-journals free of charge through the PERI project of INASP.

At present major bibliographic and documentation products of National Library ex.: bibliographies, directories and indices are in print and digital formats or only in digital format. Accordingly Sri Lanka National Bibliography (English section), Sri Lanka Postgraduate Theses Index, Sri Lanka Newspaper Article Index, Sri Lanka Conference Index, Directory of Government Publications and Index on Devolution of Power and Ethnic Conflict are in digital format.

National Library catalogue has been computerized and can be accessed through OPAC. The national Union Catalogue has been compiled and maintained by the NLDC. It can also be accessed through National Library web.

The photographic collection of National Library which consists of a large number of photographs taken at various functions of the National Library during the last two decades have also been digitized. 


\section{National Library Digitisation Project}

The National Library's role is to develop and maintain a national collection and make this material available to all Sri Lankans. So National Library has commenced a document scanning project recently and in the process of developing a digital library. Project planning, identification of required equipments, formulating the digitization policy for National Library, Selection of materials for digitization were completed during the year 2005. This year project has been implemented.

\section{Objectives of the project}

1. Enable users, regardless of location, to directly access and use digitised materials relating to Sri Lanka and Sri Lankans.

2. Increase access to help and to preserve rare and fragile collections by providing digital surrogates.

3. To facilitate exchange of information with other institutions and collaboratively build a critical mass of digital items in particular subjects.

\section{Digitisation Policy}

A policy for digitization and collection management was formed with help of digitization advisory committee which consisted of little expertise in the library and information field. Policy describes the objectives of digitisation, main principles, materials to be digitized, selection criteria for digitization, methods of accessibility to digitized materials, and standards to be used. According to the principles the main purpose of digitization activities will be to enhance access to the library's collections. Secondary purpose will be to preserve rare and fragile collections items by providing digital surrogates. Highest priority in digitization will be accorded to materials relating Sri Lanka and created by Sri Lankans and those with unique to Sri Lanka. Digitization will be undertaken without violating the copyright act of Sri Lanka.

\section{Selection of materials to be digitized}

Mainly manuscripts are selected for digitization in the first phase of the project.

At present folk lore collection of the NLDC is being digitized. This collection contains books, Journal and newspaper articles, manuscripts, CDs, audio tapes related to folk literature in Sri Lanka as well as in other countries. It also contains manuscripts written by Mr. Peter Wijesinghe who was the editor of 'Sri Lanka' Magazine. He was a researcher in the field of folk literature and was able to gather very comprehensive collection of folk literature from all over the island. Different aspects of folk literature were written in separate volumes such as Hen govithena, Kurahan govithena, Pel kavi, Goyam Kavi, Pan Viyamana, Wev Shilpaya etc. It's an unique and rare collection and it reveals the Sinhalese culture 
and indigenous knowledge of Sri Lanka. So these manuscripts have been selected for digitizing as they comply to digitization policy of NLDC. In future, palm leaf manuscripts of National Library, and old gazette collection will be digitized accordingly.

\section{Access to digitized collections}

Digitized collections will be arranged in the ways that are easy for users to access and navigate. Digitised items will be linked to catalogue of the National Library, if it is accordance with copy right act. Rest of the digitized items will keep close access. However in near future a database of digitized items will maintain for easy retrieval.

\section{Standards}

National Library is committed to maintaining appropriate standards for managing information materials. To maintain long term preservation that means the accessibility to the digitized items will depend on suitable standards. Accordingly the library will adhere to established internationally accepted standards.

Digital master files which created by the direct result of image capture, are to represent the original as accurately and faithfully as possible, to serve as a long term archival record and as a sources for creating derivative images. TIFF, uncompressed format is used to create digital master files. Derivative images are generally needed for providing access to the end users via computer networks. Frequently those images use loose compression file formats and resized to enhance delivery speed. JPEG, medium compression, 600 - 800 pixels file format is used for digital derivative images especially for manuscripts.

\section{Image Capture Device}

\section{Scanner}

There are various forms of scanners for these specific purposes such as flat bed, drum and face-up scanners. Flat bed scanner is used for document scanning and scanning of photographs.

\section{Digital Camera}

Instead of expensive, sophisticated face-up scanner, high resolution camera is used for scanning of manuscripts. Digital camera is an effective form of digital copying specially for larger items. Camera is fixed to a tripod. A book stand has been made in house with adjustable arms. This book stand acts as a book cradle in large book scanner. So the focusing distance between the camera and the book could be changed. The camera is directly linked with the PC so as to facilitate remote shooting. Then after all adjustments have been made, the person who does scanning needs only to turn the page. However it is a very cheap device compare to face-up book scanner.

Digital camera has the capability of meeting the recommended specifications for creating digital mater files, when in use, settings made 
to achieve this. Digital camera is regularly calibrated to ensure image quality.

\section{Hardware and Software}

High performance digital camera and personal computer are mainly used for the project. Digital camera with high sensitivity and high resolution is used for image capturing. Recording system of camera is JPEG or RAW. Pentium 4 with $40 G B$ hard disk PC is used to create digital files. Camera software for image capturing and Adobe photoshop full version is used as image editing software. Adobe Acrobat is used for creating pdf files.

\section{Steps of Digitisation}

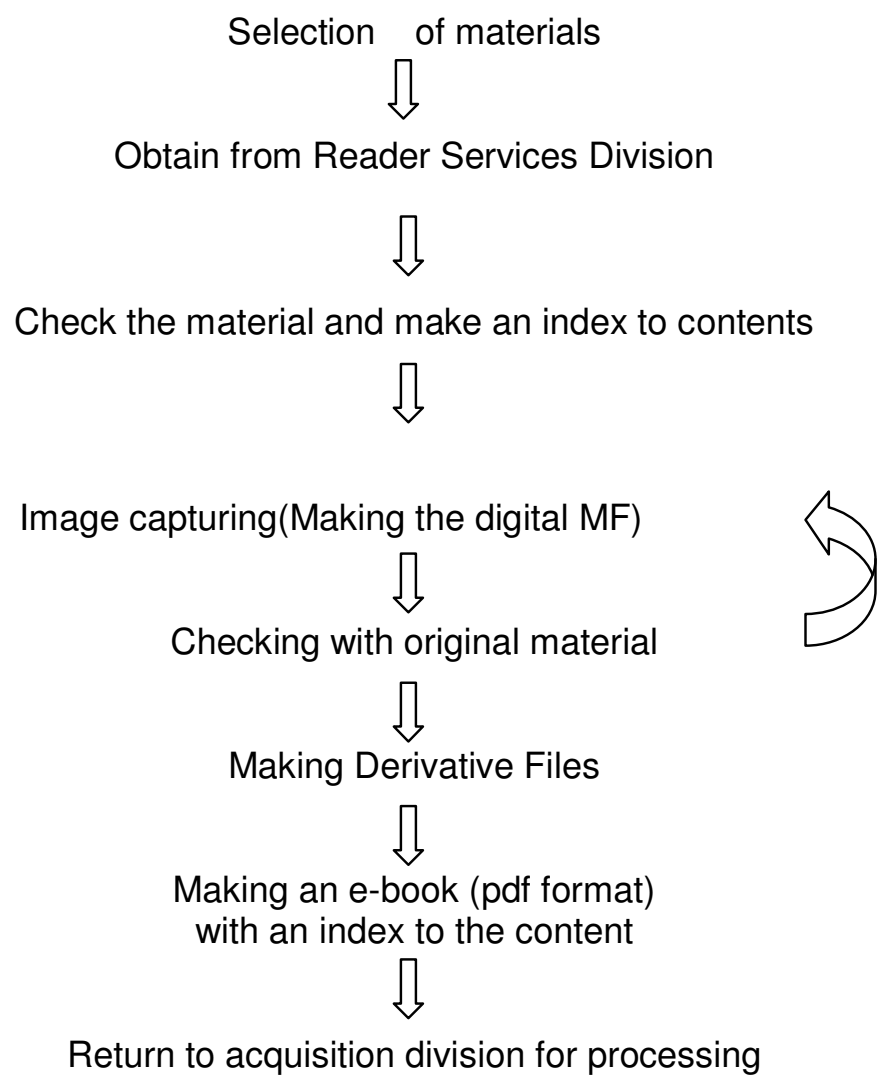

\section{Next Step}

National Library plans to create at a database of digital collections. Some of the digitized items will be linked to web if the digitized items are not violating the copyright law. National library also plans to develop a digital library on folk lore in Sri Lanka. 


\section{References}

Digitization guidelines for creating digital still images. (online). (URL http://www.natlib.nz/en

Digitization policy $2000 \quad-2004$, (online). (URL http:// www.nla.gov.au/policy/digitisation) Accessed on 13.09.2005

Gerald, Sara and Ebdon, Richard, (Ed.s) (1999).IFLA / UNESCO, survey on digitization and preservation. International Preservation Issues, - pp $1-15$

Jawaid, Ch Ahrarul Hasan ( ). Digital resources and its archiving in the national library - pp 139-147.

Amarasiri. M.S.U. Sri Lanka-country paper: the $2^{\text {nd }}$ regional training workshop on the preservation of and access to the documentary heritage in Asia and the Pacific, Seoul, Repblic of Korea, 4-7 September 2004.

Shukla, V.N. and Arora, Karunesh Kumar ( ), Digital handling of national Library resources, - pp 422 -432.

Weber, Hartmut and Dorr, Marianne (1997). Digitisation as a means of Preservation. Amsterdam. European commission on Preservation and Access. 